\title{
Health-related morphological characteristics and physiological fitness in connection with nutritional, socio-economic status, occupational workload of tea garden workers
}

\author{
Pallav Sengupta, Sobhana Sahoo
}

Department of Physiology, Vidyasagar College for Women, University of Calcutta, Kolkata, West Bengal, India

\begin{abstract} more than two years. laborers. poor nutritional status (BMI and WHR)

DOI: http://dx.doi.org/10.4314/ahs.v14i3.9

\section{Introduction}

From time immemorial, tea has been eulogized in so many ways. According to the eighteenth century english poet william cowper, 'it is the cup that cheers, but not inebriates'. ${ }^{1}$ The tea of west bengal is well-known for its taste and flavor which is as exotic and mysterious as the hills of darjeeling themselves. Among the teas cultivated in india, the most celebrated one comes from darjeeling himalaya and dooars of north bengal. In consort with tea gardens, plenteous tea factories have been established in these areas. While in tea gardens, the majority of workers are female, the laborers who are
\end{abstract}

Background: Reports on the cardiorespiratory fitness and body composition of male workers engaged in processing of tea leaves in factories within the tea-estates of West Bengal, under the influence of physiological workload, are quite scanty.

Objectives: This cross-sectional study was conducted to evaluate morphometric characteristics based on physiological status and physical fitness of tea factory laborers who are continuously exposed to tea dust in their work environment for

Methods: Subjects were divided into control and tea garden workers groups. Height and weight were measured and the body mass index (BMI) was computed. Physiological parameters such as resting heart rate, blood pressure, fitness variables like physical fitness index (PFI), energy expenditure (EE), handgrip strength and anthropometric parameters like mid-upper arm (MUAC), thigh circumference (TC), head circumference (HC) and waist-to-hip ratio (WHR) were measured.

Results: Body surface area (BSA), BMI, body fat percentage and fitness variables (PFI, EE) showed significant difference $(\mathrm{p}<0.05)$ between the two groups. Anthropometric measures (MUAC, TC, HC, WHR) reflected poor status among

Conclusions: The present study shows that the majority of workers had ectomorph stature, good physical fitness, but had

Key words: anthropometry; blood pressure; body mass index; body surface area; physical fitness; tea.

\section{* Corresponding author:}

Pallav Sengupta

Department of Physiology

Universal College of Medical Sciences \& Teaching

Hospital Tribhuvan University Ranigaon, Bhairahawa

Siddharthanagar 32900, Nepal

E-mail address: sunny_pallav_1984@yahoo.co.in extensively exposed to tea dust, in adjacent tea factories, are male. The major classes of male tea factory workers, found in those tea estates, include: operators, fitters, administrative, blenders and others, such as forklift drivers and warehouse employees ${ }^{2}$. Unfortunately, the life situation of these tea laborers is not as good ideal as it should be in our country and especially in west bengal. The tea workers of dooars are among the most exploited laborers in india. The tea laborers, live in villages inside tea estates which are located in the hinterland, and this contributes to backwardness and exploitation by the tea planters. Without the basic amenities of life, the workers live in impoverishment and often die in obscurity. Illiteracy, poverty, addiction of male and females to beer, poor standards of living are the immutable problems in their lives ${ }^{2,3}$.

However, in the tea factories strenuous work is performed by male workers, in traditional ways without knowing the effect of chronic dust exposure on health. As a result of this strenuous work, leisure of the worker decreases and the health is also affected ${ }^{3}$. Besides, dooars is located at about 61 meters above sea level in a cold temperate climate which may also affect the physical and physiological fitness along with the effects of their workload and other exposures in the working 
environment. There are very few reports about the health status of tea workers in west bengal. In addition, reports about the overall physical fitness pattern with special reference to respiratory and cardiac parameters are scanty. Thus, the present study sought to determine the physical fitness of male tea garden workers and to test the effect of workload on the physical fitness of workers.

\section{Subjects and methods}

The present study was carried out in young adults (18-24 years of age). The subjects were divided into two groups: control $(n=24)$ and tea garden workers $(\mathrm{n}=29)$. Young adult male tea garden workers (age

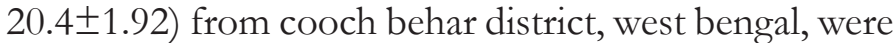
randomly selected to participate in the present study. Control subjects were also randomly selected from college students (age of 21.9 \pm 2.25 ) of kolkata, west bengal. To avoid the specific dynamic action (sda) of food, instruction was given to all the subjects to take their last meal at least two hours before conducting the test. To reduce the seasonal influence on fitness pattern, all the experiments were carried out and measurements were taken in temperature of $20^{\circ}-25^{\circ} \mathrm{c}$ and relative humidity of about $45-50 \%$ in the winter season in india. The experimental protocol was explained to them to allay their apprehension. Consent from each participant was taken for conducting the study and the experiments were carried out following institutional ethical approval. Each measurement was taken three times and the mean was represented as final result to minimize bias.

The body mass index (bmi) was computed using the following formula': bmi $=$ mass $(\mathrm{kg}) /(\text { height in } \mathrm{m})^{2}$ Total body fat percentage (tbf $\%$ ) was calculated by a predictive formula using bmi, age, and gender ${ }^{5}$ : $t b f \%=$ $(1.20 \times$ bmi $)+(0.23 \times$ age $)-10.8-5.4$ (for male subjects) . Dubois \& dubois formula was used to estimate body surface area (bsa) ${ }^{6}$. Resting heart rate was recorded after five minutes of rest; when two successive heart rate scores became equal at carotid pulse $\mathrm{p}^{7}$. Arterial blood pressure was measured using a sphygmomanometer ${ }^{8}$. Physical fitness index (pfi) was calculated from successive heart rates, measured after performing harvard step test (hst) developed by brouha et al. ${ }^{9}$. Anaerobic power was calculated by performing margaria double step test ${ }^{10}$. $\mathrm{VO}_{2 \max }{ }^{11}$ was predicted from the nomogram of astrand. Energy expenditure was determined by a formula using peak heart rate scores recorded during hst ${ }^{12}$ : ee (kcal min $\left.{ }^{-2}\right)$ $=-1.42+(0.045 \times$ peak h.r $)$. Hand grip strength was determined by using a hand grip dynamometer to test the maximum voluntary contraction. The best of three trials was accepted with three minutes rest in-between. All the hand grip measurements were taken with the arm straight, i.e. At $0^{\circ}$ elbow-angle.

Curvilinear distances were taken around the midpoint of upper arm (muac), thigh (tc), calf muscle (cc), waist (wc), buttock (bc) and head (hc) measuring steel tape ${ }^{13}$. A sliding caliper was used for the measurement of head anthropometry parameters (length and breadth). To measure the percentage of spinal shrinkage, recumbent length was measured on a wooden desk fixed to the wall after a uniform settling down period of 2 minutes fixed arbitrarily. Measurement was taken with the help of anthropometric rod. Spinal shrinkage was measured as the difference between the recumbent length and the standing height. Percentage spinal shrinkage was calculated as :[( recumbent length standing height $) \times 100] /$ recumbent length.

Data are expressed as mean \pm sd. Comparison of parameters between control and male tea garden workers was done by two tailed unpaired $t$-test, using microsoft excel- 2007 and the result was considered as statistically significant when the two-tailed $p$-values are equal or less than $0.05^{14}$.

\section{Results}

All the respondents under the present study were employed as casual laborers in the tea estates more than two years. The mean age, height and weight of the respondents were $20.4 \pm 1.9$ years, $163.5 \pm 7.2 \mathrm{~cm}$ and $48.3 \pm 3.1 \mathrm{~kg}$, respectively. It was revealed that $58.6 \%$ of the male tea garden workers were educated up to or above primary school. Most of the adult male workers who participated in this study were non-smokers $(75.9 \%)$ (table 1$)$. 
Table 1. Socio-demographic characteristics of the tea garden workers.

\begin{tabular}{ll}
\hline \multicolumn{1}{c}{ Variables } & $\mathbf{N}(\mathbf{\%})$ \\
\hline Work experience (years) & $17(58.62)$ \\
$2-2.5$ & $05(17.25)$ \\
$2.5-3$ & $07(24.13)$ \\
$\geq 3$ & \\
- Education & $12(41.37)$ \\
No formal schooling & $17(58.63)$ \\
Primary or above & \\
Per capita income of family & \\
(indian rupees) & $08(27.58)$ \\
$<500$ & $21(72.42)$ \\
$\geq 500$ & \\
Smoking & $07(24.13)$ \\
Yes & $22(75.86)$ \\
No & \\
& \\
Total & $=29(100)$ \\
\hline
\end{tabular}

Among the physical and physiological parameters the body weight, bmi, tbf \%, bsa, rhr, energy expenditure,

handgrip strength (both right and left) were found significantly higher $(\mathrm{p}<0.05)$ in tea garden workers than significantly lower whereas, pfi and $\mathrm{vo}_{2 \max }$ were found in the controls (table 2). 
Table 2. Body composition determinants and physical fitness variables of control subjects and tea factory laborers.

Values are mean \pm sd, sample size $\left(\mathrm{n}_{1}=24 ; \mathrm{n}_{2}=29\right)$. Superscript $\left.{ }^{\dagger}\right)$ indicates significant difference by

parameters two tail unpaired t-test at $p<0.05$ (ns $=$ not significant).

Height (cm)

Body weight (kg)

Bmi $\left(\mathrm{kg} / \mathrm{m}^{2}\right)$

Body fat \%

Bsa $\left(\mathrm{m}^{2}\right)$

Resting heart rate (beats/min)

Systolic blood pressure ( $\mathrm{mm}$ hg )

Diastolic blood pressure ( $\mathrm{mm} \mathrm{hg}$ )

Pfi

Anaerobic power $\left(\mathrm{kg} \cdot \mathrm{m}^{-1} \cdot \mathrm{sec}^{-1}\right)$

$\mathrm{Vo}_{2 \max }\left(\right.$ liters.min $\left.{ }^{-1}\right)$

Energy expenditure (k.cal. $\mathrm{Min}^{-2}$ )

Right hand grip strength (kg)

left hand grip strength (kg)

\section{Control} $(\mathrm{n}=24)$

$164.6 \pm 7.21$

$59.3 \pm 7.50$

$21.7 \pm 1.93$

$20.4 \pm 1.74$

$1.68 \pm 0.08$

$76.2 \pm 8.10$

$123.0 \pm 4.62$

$84.1 \pm 6.84$

$69.9 \pm 4.80$

$12.3 \pm 2.46$

$3.12 \pm 0.33$

$5.67 \pm 0.57$

$38.3 \pm 2.79$

$30.2 \pm 1.89$
Tea factory workers $(n=29)$

P-values

$\begin{array}{cc}163.5 \pm 7.24^{\mathrm{ns}} & 0.093 \\ 48.3 \pm 3.12^{\dagger} & 0.033 \\ 18.3 \pm 2.22^{\dagger} & 0.047 \\ 17.7 \pm 1.71^{\dagger} & 0.009 \\ 1.49 \pm 0.09^{\dagger} & 0.045 \\ 73.6 \pm 6.00^{\dagger} & 0.007 \\ 124.1 \pm 2.61^{\mathrm{ns}} & 0.123 \\ 83.1 \pm 9.18^{\mathrm{ns}} & 0.105 \\ 79.2 \pm 6.42^{\dagger} & 0.001 \\ 13.2 \pm 3.42^{\mathrm{ns}} & 0.453 \\ 3.19 \pm 0.38^{\dagger} & 0.027 \\ 4.50 \pm 0.72^{\dagger} & 0.002 \\ 24.8 \pm 2.46^{\dagger} & 0.009 \\ 24.6 \pm 2.07^{\dagger} & 0.015\end{array}$

with respect to their corresponding controls. They also showed significantly higher spinal shrinkage than the control subjects (table 3). tc, wc, bc, head breadth (table 3) were found significantly lower, but significantly higher head circumference and head length was observed in case of tea factory workers

Table 3. Morphometric characters of control subjects and male tea factory laborers. Values are mean \pm sd, sample size $\left(\mathrm{n}_{1}=24 ; \mathrm{n}_{2}=29\right)$. Superscript $\left(^{*}\right)$ indicates significant difference by two tail unpaired t-test at $p<0.05$ (ns $=$ not significant).

$\begin{array}{lccc}\text { Parameters } & \begin{array}{c}\text { Control } \\ (\mathbf{n}=\mathbf{2 4})\end{array} & \begin{array}{c}\text { Tea factory workers } \\ (\mathbf{n}=\mathbf{2 9})\end{array} & \text { P-values } \\ \begin{array}{l}\text { mean upper arm } \\ \text { circumference }(\mathbf{c m})\end{array} & 27.0 \pm 4.11 & 24.1 \pm 2.70^{*} & 0.043 \\ \text { Thigh circumference }(\mathbf{c m}) & 47.1 \pm 5.49 & 44.7 \pm 4.02^{*} & 0.036 \\ \text { Calf circumference }(\mathbf{c m}) & 32.7 \pm 3.54 & 31.8 \pm 2.52^{\mathrm{ns}} & 0.126 \\ \text { Waist circumference }(\mathbf{c m}) & 75.9 \pm 4.53 & 71.4 \pm 4.65^{*} & 0.047 \\ \text { Waist-to-hip ratio (whr) } & 0.94 \pm 0.02 & 0.90 \pm 0.01^{*} & 0.027 \\ \text { Head circumference }(\mathbf{c m}) & 52.5 \pm 4.23 & 56.2 \pm 4.08^{*} & 0.021 \\ \text { Head breadth }(\mathbf{c m}) & 16.2 \pm 2.04 & 15.5 \pm 2.22^{*} & 0.039 \\ \text { Head length }(\mathbf{c m}) & 19.2 \pm 2.73 & 20.7 \pm 2.52^{*} & 0.047 \\ \text { Spinal shrinkage } \mathbf{( \% )} & 0.83 \pm 0.06 & 1.86 \pm 0.08^{*} & 0.007 \\ \text { Buttock circumference } & 81.3 \pm 6.03 & 78.0 \pm 1.92^{*} & 0.046\end{array}$

(cm) 


\section{Discussion}

In contrast to undergraduate college students, tea factory workers were found to have significantly low body weight, BMI, BSA and 7BF $(p<0.05)$ which may be a result of heavy physical workload or their poor socio-economic condition which is reflected in their per capita income. Resting heart rate is a useful parameter of cardiovascular homeostasis ${ }^{15}$ which tends to get lower in heavy workers ${ }^{16}$, as reflected in our study. Tea garden workers showed a significantly lower resting heart rate $(73.6 \pm 6.00)$ than control subjects $(\mathrm{p}=0.007)$. Conversely, $\mathrm{vo}_{2 \max }(3.19 \pm 0.38)$ was found to be significantly higher in tea factory laborers, which may have some correlation with the findings of bailey et al. ${ }^{17}$ who have found that lower $\mathrm{vo}_{2 \max }$ levels in men were associated with an increased probability of being overweight or obese. Therefore, it can be presumed that higher body weight of control subjects, in the present study, thus, influenced their oxygen uptake capacity ${ }^{18}$. Systolic and diastolic pressures showed no significant change in respondents ( $p>0.05)$. In contrast, their pulse rate recovered quickly, which is an indicator of better fitness and reflected in significantly higher pfi (79.2 $\pm 6.42)$ and lower energy expenditure $(4.50 \pm 0.72)$ than sedentary workers ${ }^{19-21}$. They also showed lower handgrip strength in both right and left hand.

Low waist circumference (WC) and buttock circumference (BC), and thus less waist-to-hip ratio (whr) shows ectomorphic body composition. In addition, mid upper arm circumference (MUAC) and thigh circumference (TC) which are the measures of protein storage in the body are significantly low $(p<0.05)$, which is the indicator of malnutrition. The craniofacial anthropometric measures showed less body growth in tea garden workers. They showed significantly higher head circumference and head length, but lower head breadth $(\mathrm{p}<0.05)$, which is an indicator of lower head volume and thus, lower protein composition. Tea garden workers also showed significant spinal shrinkage $(1.86 \%)$ than control subjects $(0.83 \%)$, which may be due to working stature. Most of the workers perform their work in standing posture for more than 6 hours a day. There is a gain in stature during relaxed sitting compared to work in a sitting posture. The load on the spine is greatest when work in a standing position is performed. The greater shrinkage of the lumbar spine during work in a standing position compared to a sitting posture is probably due to the effect of bending and torsion while handling the work materials ${ }^{22}$.

There is limited evidence of pulmonary dysfunction of tea factory workers due to the exposure of tea dust ${ }^{23,24}$. As the mean age of the subjects from studied population belongs to young adult category, the effect of tea dust is not too high to modulate the physical fitness parameters. Therefore from the present study it can be concluded that although tea factory workers have good fitness, few have signs of malnutrition. However more detailed studies including a larger sample size, considering socio-economic conditions, nutritional status and age group is essential to draw any definite inference.

\section{Conflict of interest/competing interest}

Authors declare that they do not have any conflict of interest about the publication of this article.

\section{References}

1. Cowper w. The task;1785:part iv: line 34.

2. Gupta vn. Women labour in tea plantations. Social welfare. 1980; 37: 2-3.

3 . Roy d. Role and status of women in an agroindustrial context. Man in india 2001; 81: 139-151.

4. Eknoyan g. Adolphe quetelet (1796-1874) - the average man and indices of obesity. Nephrol dial transplant. 2008; 23: 47-51.

5. Deurenberg p, westrate ja, seidell jc. Body mass index as a measure of body fatness: age- and sex-specific prediction formulas. Br j nutr. 1991; 65:105-114.

6. Du bois $\&$ du bois. A formula to estimate the approximate surface area if height and weight be known. Arch intern med 1916; 17: 863.

7. Sengupta $p$, chaudhuri $p$, bhattacharya k. Male reproductive health and yoga. Int j yoga 2013; 6(2): 8795.

8. Booth j. A short history of blood pressure measurement. Proceedings of the royal society of medicine. 1977; 70 (11): 793-9.

9. Brouha i, health cw, gray b. A step test simple method of measuring physical fitness for hard muscular work in adult men. Rev canadian biol. 1943; 2: 86.

10. Margaria $r$, aghemo p, rovelli e. Measurement of muscular power (anaerobic) in man. J appl physiol. 1966; 21: 1662-64.

11. Astrand po, rodahl k, dahl h, stromme s. Test book of work physiology. $4^{\text {th }}$ ed, 1960. P. 281.

12. Sengupta p, sahoo s. A cross sectional study to evaluate the fitness pattern among the young fishermen of coastal orissa. Indian j pub health res dev 2013; 4(1): 171-175.

13. Roy js. Epidemiological indices, anthropometric 
and cadaver estimates of body composition. Body composition in biological anthropology. Cambridge studies in biological and evolutionary anthropology. 6 . Cambridge university press 1991. Pp. 24-25.

14. Das d, das a. Statistics in biology and psychology. $4^{\text {th }}$ ed. Academic publishers, india, 2005. P. 109.

15. Sengupta p, sahoo s. Evaluation of health status of the fishers: prediction of cardiovascular fitness and anaerobic power. World j life sci med res. 2011; 1(2): 2530.

16. Chaudhuri p, sengupta p, biswas s, haldar, r. Emerging trend of gym practice and its consequence over physical and physiological fitness. Biol exer 8(1): 49-58.

17. Bailey dm, davies b, young is, jackson mj, davison $\mathrm{gw}$, isaacson r, richardson rs (2003). Epr spectroscopic detection of free radical outflow from an isolated muscle bed in exercising humans. J. Appl. Physiol. 94(5): 1714-1718.

18. Sengupta p. Assessment of physical fitness status of young sikkimese residing in high-hill temperate regions of eastern sikkim. Asian j med sci 2011; 2(3): 169-174.

19. Sengupta p. Health impacts of yoga and pranayama: an art-of-the-state review. Int j prev med 2012; 3(7):444458.

20. Sengupta p, sahoo s. A fitness assessment study among young fishermen of coastal areas of west bengal, india. South east asia j pub heal 2011; 1(2): 28-34.

21. Sengupta p. Environmental and occupational exposure of metals and their role in male reproductive functions. Drug chem toxicol 2012; 36(3): 353-368.

22. Sengupta p, bhattacharya k. Effects of high altitude and nutritional status over the physical fitness of young residents of pokhara, western nepal. South east asia j pub bealth 2012; 2(1): 34-38.

23. Jayawardana $\mathrm{p} l$ and udupihille, ventilatory function of factory workers exposed to tea dust, occup.med. 1997; 47:105-109.

24. Sengupta p. Challenge of infertility: how protective the yoga therapy is? Ancient sci life 2012; 32 (1):61-62. 